\title{
Gambaran Faktor - Faktor Keterlambatan Waktu Penyediaan Berkas Rekam Medis Poliklinik Jantung Di Rumah Sakit Rafflesia Kota Bengkulu Tahun 2017
}

\author{
Nova Oktavia, Siska Septiani \\ Akademi Kesehatan Sapta Bakti Bengkulu, Prodi Rekam Medis dan Informasi Kesehatan \\ Email : nova.oktavia80@gmail.com
}

\begin{abstract}
ABSTRCAT
Berdasarkan observasi secara langsung di unit rekam medis (RM) Rumah Sakit Rafflesia Bengkulu pada proses penyediaan berkas rekam medis (BRM) untuk pasien rawat jalan poliklinik jantung dari 10 BRM yang diamati terdapat 8 BRM yang melebihi standar waktu penyediaan yaitu 10 menit. Tujuan penelitian ini adalah untuk mengetahui gambaran faktor - faktor keterlambatan waktu penyediaan BRM poliklinik jantung diRumah Sakit Rafflesia Kota Bengkulu Tahun 2017. Jenis penelitian yang digunakan adalah Observasional Deskriptif dengan rancangan Cross-Sectional, Populasi dalam penelitian yaitu 10 petugas RM yang melayani pasien rawat jalan dan BRM yang disediakan oleh petugas rawat jalan, sampel sebanyak 105 BRM poliklinik jantung dengan teknik pengambilan Non Probality sampling dengan jenis Consecutive sampling. Menggunakan data primer, diolah secara univariat. Penelitian dilaksankan bulan Juli Tahun 2017 di Rumah Sakit Rafflesia Kota Bengkulu, bertempat dipendaftaran pasien rawat jalan. Hasil analisa univariat, dari 10 petugas RM rawat jalan hanya satu berpendidikan $D$ III Rekam Medis dan mayoritas masa kerja petugasnya $\leq 5$ tahun, pada saat pengambilan BRM di ruangan filing, dari $105 \mathrm{BRM}$ mayoritas berkas sulit ditemui pada rak penyimpanan yaitu $62 \quad(59,1 \%)$ BRM dan 105 BRM $62(59,1 \%)$ berkas lambat disediakan oleh petugas rawat jalan. Diharapkan penambahan SDM lulusan D III RM dan petugas Non RM diikuti pelatihan atau seminar, Sebaiknya ada tanda petunjuk untuk berkas keluar (outguide/tracer).
\end{abstract}

Kata Kunci: Berkas Rekam Medik, Waktu Penyediaan, Rawat Jalan

\section{PENDAHULUAN}

Rumah sakit adalah institusi pelayanan kesehatan yang menyelenggarakan pelayanan kesehatan perorangan secara paripurna yang menyediakan pelayanan rawat inap, rawat jalan dan gawat darurat (Peraturan Menteri Kesehatan Nomor 340/MENKES/PER/III/2010). Fungsi rumah sakit itu sendiri adalah tempat menyelenggarakan pelayanan medik, pelayanan penunjang, pelayanan keperawatan, pelayanan rehabilitasi, dan pelayanan pencegahan penyakit, sehingga memerlukan manajemen yang baik dalam pengelolaannya (Jacobalis, 2000).

Kemenkes No 377/Menkes/SK/III/2007 tentang Standar Profesi Perekam Medik dan Informasi Kesehatan, Perekam Medis harus mampu mengelola unit kerja yang berhubungan dengan perencanan, pengorganisasian, penataan dan pengontrolan unit kerja manajemen informasi kesehatan (MIK) / rekam medis (RM) di instalansi pelayanan kesehatan. Penyelenggaraan rekam medis adalah merupakan proses kegiatan yang dimulai pada saat diterimanya pasien di rumah sakit, diteruskan kegitan pencatatan data medis pasien selama pasien itu mendapatkan pelayanan medis di rumah sakit, dan dilanjutkan dengan penanganan berkas rekam medis yang meliputi penyelenggaraan penyimpanan untuk melayani permintaan dari pasien atau untuk keperluan lainnya (Depkes RI, 1997).

Peraturan Menteri Kesehatan Republik Indonesia nomor 269/MENKES/PER/III/2008 tentang rekam medis, bahwa rekam medis adalah berkas yang berisikan catatan dan dokumen tentang identitas pasien, pemeriksaan, pengobatan, tindakan, dan pelayanan lain yang telah diberikan kepada pasien. Rekam medis dapat berupa rekaman dalam bentuk sistem informasi yang dapat digunakan untuk mengumpulkan segala informasi pasien terkait 
pelayanan yang diberikan di fasilitas pelayanan kesehatan sehingga dapat digunakan untuk berbagai kepentingan, seperti pengambilan keputusan pengobatan kepada pasien, bukti legal pelayanan yang telah diberikan, dan dapat juga sebagai bukti tentang kinerja sumber daya manusia di fasilitas pelayanan kesehatan.

Menurut Wursanto (2007), guna mendukung agar rekam medis dapat dijaga dan dikelola dengan baik maka diperlukan sistem penyimpanan yang baik pula dengan didukung oleh sumber daya manusia yang handal. Sumber daya manusia dalam pengelolaan rekam medis adalah tenaga kesehatan yang paham dan berkompeten dalam sistem rekam medis. Tenaga kesehatan adalah setiap orang yang mengabdikan diri dalam bidang kesehatan serta memiliki pengetahuan dan keterampilan melalui pendidikan formal di bidang kesehatan yang untuk jenis tertentu memerlukan kewenangan dalam melakukan upaya kesehatan (Depkes, 2004).

Hasil penelitian Susanti (2013), didapatkan bahwa dari 11 orang petugas rekam medis di RS PDHI Yogyakarta 4 $(36,4 \%)$ diantaranya masih berpendidikan SMA dan mempunyai kinerja yang kurang baik. Pendidikan memberikan pengetahuan bukan saja yang langsung dengan pelaksanaan tugas, tetapi juga landasan untuk mengembangkan diri serta kemampuan memanfaatkan semua sarana yang ada di sekitar kita untuk kelancaran tugas. Semakin tinggi pendidikan semakin tinggi produktivitas kerja (Arfida, 2003). Hasil penelitian Susanti (2013) juga didapatkan bahwa rata-rata masa kerja petugas rekam medis di RS PDHI Yogyakarta adalah 5 tahun. Menurut Priansyah (2014), pengalaman kerja merupakan kegiatan melakukan segala sesuatu yang pernah dialami oleh seseorang. Pengalaman kerja akan memberikan keuntungan bagi seseorang dalam melaksanakan kerja selanjutnya karena setidaknya orang tersebut sudah pernah melakukan pekerjaan itu sehingga ia akan tahu tentang pekerjaan yang akan dihadapi.

Rekam medis terdiri dari beberapa unit pelayanan. Salah satu bagian dari unit pelayanan rekam medis di rumah sakit adalah Filing, di mana bagian ini bertugas untuk mengambil dan mendistribusikan dokumen rekam medis ke unit pelayanan kesehatan baik rawat jalan, rawat inap maupun rawat darurat (Menkes, 2008; Rustiyanto, 2009). Menurut Rustiyanto (2010), filing adalah kegiatan menyimpan, penataan atau penyimpanan (storage) berkas rekam medis untuk mempermudah pengambilan kembali atau retrieval. Pengambilan adalah kegiatan pengambilan berkas rekam medis di rak berdasarkan permintaan pasien yang datang untuk berobat atau untuk mendapatkan pelayanan kesehatan lainnya, agar berkas rekam medis yang keluar dari rak filing tersebut dapat dekendalikan sehingga mudah diketahui keberadaan dan penggunaanya (Wintri, 2011).

Pelayanan kesehatan di rumah sakit terdiri dari beberapa pelayanan. Salah satu pelayanan kesehatan tersebut adalah pelayanan rekam medis (Rustiyanto, 2010). Pelayanan rekam medis yang baik dan bermutu tercermin dari pelayanan yang ramah, cepat, serta nyaman. Masa kerja mempengaruhi kinerja petugas rekam medis, semakin lama bekerja maka semakin cepat dalam melayani pengambilan berkas rekam medis sehingga dapat meminimalisir waktu tunggu pasien (Siagian, 2008). Salah satu dimensi mutu pelayanan kesehatan adalah akses terhadap pelayanan yang ditandai dengan waktu tunggu pasien (Wijono, 2000). Waktu tunggu merupakan masalah yang sering menimbulkan keluhan pasien dibeberapa rumah sakit. Lama waktu tunggu pasien mencerminkan bagaimana rumah sakit mengelola komponen pelayanan yang disesuaikan dengan situasi dan harapan pasien (Kemenkes, 2007). Waktu tunggu pasien dalam hal ini terhadap pelayanan Rekam Medis di Pendaftaran Rawat Jalan merupakan salah satu hal penting yang akan menentukan citra awal pelayanan rumah sakit (Wijono, 2000).

Waktu penyediaan dokumen rekam medis pasien rawat jalan berdasarkan Menkes (2008) Tentang Standar Pelayanan Minimal (SPM) di Rumah Sakit standar waktu penyediaan berkas rekam medis pelayanan rawat jalan adalah 
kurang dari 10 menit sedangkan rawat inap kurang dari 15 menit.Waktu penyediaan tersebut dihitung mulai saat pasien selesai registrasi sampai dokumen rekam medis tersebut sampai ke poliklinik yang dituju. Waktu tunggu pasien merupakan salah satu komponen yang potensial menyebabkan ketidakpuasan pasien akan menganggap pelayanan kesehatan jelek apabila sakitnya tidak sembuh - sembuh, antri lama, dan petugas kesehatan tidak ramah meskipun profesiona. Kepuasan adalah tingkat keadaan yang dirasakan seseorang yang merupakan hasil dari membandingkan penampilan atau outcome yang dirasakan dalam hubungannya dengan harapan seseorang (Wijono,2000).

Berdasarkan observasi secara langsung di unit rekam medis Rumah Sakit Rafflesia Bengkulu pada proses penyediaan berkas rekam medis untuk pasien rawat jalan poliklinik jantungdari 10 berkas rekam medis yang diamati terdapat 8 berkas rekam medis yang melebihi standar waktu penyediaan yaitu 10 menit.Sehingga ditemukan beberapa masalah diantaranya : (1) Berdasarkan pengamatan pada saat peraktek di unit rekam medis terdapat penumpukan berkassebelum di distribusikan ke poliklinik jantung,hal ini dikarenakanmenurut petugas rekam medis untuk mengefisiensi waktudan tenaga; (2) Waktu penyediaan dokumen rekam medis menjadi lambat karena berkas rekam medis tidak tersusun rapi dirak penyimpanan, bahkan ada berkas yang terletak dibawah lantai dan lamanya penyediaan berkas rekam medis karena masih ada sistem penjajaran yang tidak beraturan sehingga menyulitkan petugas untuk menemukan berkas rekam medis yang sesuai dengan nomor rekam medisnya; (3) Tidak adanya petugas yang khusus untuk mendistribusikan berkas, bahkan ada perawat yang mendistribusikan berkas ke poliklinik jantung.

Berdasarkan uraian permasalahan diatas, maka penulis tertarik untuk melakukan penelitian tentang "Gambaran Faktor - Faktor Keterlambatan Waktu Penyediaan Berkas
Rekam Medis Poliklinik Jantung Di Rumah Sakit Rafflesia Kota Bengkulu Tahun 2017”. Penelitian ini bertujuan untuk, mengetahui gambaran faktor - faktor keterlambatan waktu penyediaan berkas rekam medis poliklinik jantung yang meliputi pendidikan dan masa kerja petugas rekam medis sistem filing : Pengambilan berkas rekam medis di Rumah Sakit Rafflesia Kota Bengkulu Tahun 2017.

\section{METODE PENELITIAN}

Jenis penelitian ini adalah Observasional Deskriptif dengan rancangan Cross-Sectional. Penelitian Observasional adalah Penelitian yang dilakukan dengan cara observasi, pengamatan dan pengukuran terhadap variabel yang diteliti. Populasi dalam penelitian ini yaitu 10 petugas RM yang melayani pasien rawat jalan dan berkas rekam medis pasien baru dan lama yang disediakan oleh petugas rawat jalan poliklinik jantung, dimana rata-rata kunjungan perbulan sebanyak 143 berkas. Sampel penelitian petugas rekam medis diambil secara total populasi sedangkan sampel berkas rekam medis sebanyak 105 BRM yang didapat dari rumus besar sampel dan diambil secara Consecutive sampling yaitu setiap pasien rawat jalan datang ke bagian pendaftaran dan BRM yang disediakan oleh petugas rawat jalan untuk masing-masing pasien sampai jumlah sampel terpenuhi. Jenis data penelitian ini adalah data primer yang diukur menggunakan lembar observasi dan pedoman wawancara. Setelah data terkumpul dianalisis secara univariat menggunakan tabel distribusi frekuensi dan dinterpretasikan. 


\section{HASIL PENELITIAN}

Tabel 1 Distribusi Frekuensi Tingkat Pendidikan dan Masa Kerja Petugas Rekam Medis di Unit Rekam Medis di Rumah Sakit Rafflesia Kota Bengkulu.

\begin{tabular}{cllcc}
\hline \multirow{2}{*}{ No } & & Variabel & Jumlah (n) & Presentase (\%) \\
\hline \multirow{2}{*}{1} & Pendidikan & & \\
\cline { 2 - 5 } & SMA & 4 & 40 \\
\cline { 2 - 5 } & D III / S1 Non RM & 1 & 50 \\
\cline { 2 - 5 } & D III RM & 10 & 10 \\
\hline \multirow{2}{*}{2} & Masa Kerja & & 100 \\
\cline { 2 - 5 } & $<5$ Tahun & 9 & 10 \\
\cline { 2 - 5 } & $\geq 5$ Tahun & 1 & 100 \\
\hline
\end{tabular}

Sumber : Data Primer Terolah 2017

Berdasarkan Tabel 1 dari 10 orang petugas rekam medis terdapat $4(40 \%)$ petugas yang berpendidikan SMA, $5(50 \%)$ petugas berpendidikan non RMIK yang terdiri dari2 orang S1 komputer \& 3 orang D
III keperawatan dan hanya 1 orang petugas berpendidikan D III rekam medis. Dari 10 petugas rekam medis, 9 orang telah bekerja selama $<5$ tahun.

Tabel 2. Distribusi Frekuensi Sistem Filing : Pengambilan Berkas Rekam Medis di Rumah Sakit Rafflesia Kota Bengkulu.

\begin{tabular}{|c|c|c|}
\hline Sistem Filling (Pengambilan) & Jumlah (BRM) & Presentase $(\%)$ \\
\hline Mudah ditemui & 43 & 40,9 \\
\hline Sulit ditemui & 62 & 59,1 \\
\hline Jumlah & 105 & 100 \\
\hline
\end{tabular}

Sumber : Data Primer Terolah 2017

Berdasarkan Tabel 3 dari 105 berkas rekam medis didapatkan bahwa $62(59,1 \%)$
BRM sulit ditemui pada rak yang ada di ruangan filing.

Tabel 3 Distribusi Frekuensi Waktu Penyediaan Berkas Rekam Medis di Poliklinik Jantung Rumah Sakit Rafflesia Kota Bengkulu.

\begin{tabular}{lccc}
\hline \multicolumn{2}{r}{ Waktu Penyediaan BRM } & Jumlah(BRM) & Presentase (\%) \\
\hline$<10$ menit & 43 & 40,9 \\
\hline \multirow{2}{*}{$\geq 10$ menit } & Jumlah & 62 & 59,1 \\
\hline & 105 & 100 \\
\hline
\end{tabular}

Sumber : Data Primer Terolah 2017 
Berdasarkan Tabel 4.3dari 105 berkas rekam medis didapatkan hasil bahwa $62(59,1 \%)$ BRM

\section{PEMBAHASAN}

1. Distribusi Frekuensi Tingkat Pendidikan dan Masa Kerja Petugas Rekam Medis.

Hasil penelitian ini didapatkan bahwa dari 10 orang petugas rekam medis rawat jalan hanya ada satu petugas berpendidikan D III RM dan sebagian besar non RM. Menurut kepala ruangan rekam medis, meskipun hanya ada 1 orang petugas rekam medis yang lulusan D III rekam medis, beberapa petugas telah mengikuti pelatihan tentang rekam medis. Menurut Grossmann (1999), semakin tinggi tingkat pendidikan, semakin mudah mereka menerima serta mengembangkan pengetahuan dan teknologi, sehingga akan meningkatkan produktivitas. Menurut Lasa (2005), pelatihan merupakan kegiatan yang lebih menekankan pada penguasaan hal-hal yang bersifat praktis/terapan.

Hasil penelitian ini juga didapatkan bahwa sebagian besar petugas rekam medis memiliki masa kerja $\leq 5$ tahun, yaitu 3 orang telah bekerja selama 2,5 tahun dan 6 orang baru bekerja $\leq 1$ tahun. Hal ini dikarenakan, menurut Kepala rekam medis, dalam waktu 2 minggu terkahir ini terjadi mutasi petugas dari rawat inap ke rawat jalan, sehingga petugas tersebut belum terlalu memahami tentang kondisi ruangan rekam medis baik dari pendaftaran, pembuatan SEP \& SJP sampai pendistribusian. Menurut Nitisemito (1996), masa kerja adalah lamanya seseorang karyawan menyumbangkan tenaganya pada perusahaan tertentu. Sejauh mana tenaga kerja dapat mencapai hasil yang memuaskan dalam bekerja tergantung dari kemampuan, kecakapan dan keterampilan tertentu agar dapat melaksanakan pekerjaan dengan baik

Hasil penelitian ini sejalan dengan hasil penelitian Giyana (2012) yang lambat dalam penyediaan berkas rekam medis dari pendaftaran sampai berkas didistribusikan.

menyatakan bahwa petugas di bagian filling mengatakan belum pernah mengikuti pelatihan khusus untuk filling. Di Rumah Sakit Kota Semarang, yang bertugas sebagai koordinator Filling Rawat Inap berusia 47 tahun, pendidikan terakhir SMA dan telah bekerja di ruang filling selama 19 tahun. Masa kerja dikaitkan dengan waktu mulai berkerja dan berkaitan erat dengan pengalaman yang didapat selama menjalankan tugas, petugas rekam medis yang berpengalaman dipandang lebih mampu melaksanakan tugas. Semakin lama seseorang bekerja maka semakin tinggi pula produktivitasnya karena semakin berpengalaman dan mempunyai keterampilan yang baik dalam menyelesaikan tugas yang dipercayakan kepadanya (Siagian, 2008)

\section{Distribusi Frekuensi Sistem Filing :} Pengambilan Berkas Rekam Medis

Hasil penelitian didapatkan bahwa dari 105 berkas rekam medis mayoritas berkas sulit ditemui. Penyebab berkas rekam medis sulit ditemui, diantaranya berkas rekam medis tidak tersusun rapi pada rak penyimpanan; berkas berada pada rak yang tinggi, sehingga sulit untuk diambil; bahkan ada berkas yang terletak dibawah lantai karena belum disusun oleh petugas filing dan masih ada sistem penjajaran yang tidak beraturan sehingga menyulitkan petugas untuk menemukan berkas rekam medis sesuai dengan nomor rekam medisnya. Hasil penelitian ini sejalan dengan hasil penelitian Andrian (2015) di RSUD Soekardjo Tasik Malaya, didapatkan bahwa sistem penjajaran di RSUD Tasikmalaya masih tidak beraturan sehingga masih menyulitkan petugas untuk menemukan berkas rekam medis yang sesuai dengan nomor rekam medisnya. Selain itu berkas rekam medis yang masih 
aktif tercecer dibawah lantai karena fasilitas rak penyimpanan yang kurang dan masih belum cukup untuk menampung berkas rekam medis

Hasil penelitian Giyana (2012) yang menyatakan bahwa berdasarkan hasil observasi di RSUD Kota Semarang didapatkan bahwa sarana dan prasarana untuk mendukung kerja petugas tersedia tapi belum terpenuhi misalnya dari hasil observasi dan didukung dengan hasil wawancara dibagian Filling pencahayaan kurang, panas, kurang nyaman dan tempat penyimpanan juga masih kurang karena masih banyak berkas-berkas yang belum ditempatkan di rak penyimpanan dokumen

Hasil penelitian ini juga didapatkan bahwa pada saat peneliti mengamati berkas yang ada pada rak tidak adanya tracer/outguide sehingga berkas tidak diketahui keberadaanya diruangan filing, dan beberapa berkas rekam medis diketahui keberadaan nya yaitu dipinjam oleh petugas di ruang BPJS dan masih ada berkas rekam medis di ruangan poliklinik yang belum dikembalikan. Menurut Depkes RI (2006), petunjuk keluar adalah suatu alat yang penting untuk mengawasi penggunaan rekam medis.Dalam penggunaannya "Petunjuk Keluar/Tracer/Outguide" ini diletakkan sebagai pengganti pada tempat berkas rekam medis yang diambil (dikeluarkan) dari rak penyimpanan. Kartu pinjam/ petunjuk keluar tetap berada di rak file tersebut sampai berkas rekam medis yang diambil (dipinjam) kembali ke tempat semula.

3. Distribusi Frekuensi Waktu Penyediaan Berkas Rekam Medis

Hasil penelitian ini didapatkan bahwa dari 105 berkas rekam medis,mayoritas berkas rekam medis poliklinik jantung lambat disediakan oleh petugas pendaftaran. Hal ini sejalan dengan hasil penelitian Andrian (2015) di RSUD Tasikmalaya, bahwa dari 99 berkas rekam medis, sebanyak 63 BRM $(63,64 \%)$ pasien rawat jalan lambat disediakan. Hasil penelitian Sudrajat \& Sugiarti (2014) menunjukan bahwa terdapat 58,72\% dokumen yang terlambat penyediaannya dan jumlah responden yang merasa tidak puas dengan pelayanan petugas rawat jalan adalah $70,36 \%$. Hal ini disebabkan karena jumlah kunjungan yang terus meningkat setiap harinya tidak diimbangi dengan penambahan petugas penyedia dokumen rekam medis, sistem penjajaran yang tidak berurutan dan tidak adanya tracer serta buku peminjaman dokumen rekam medis. Kepuasan pasien adalah nilai subyektif terhadap kualitas pelayanan yang diberikan. Penilaian itu dilandasi oleh hal seperti : pengalaman masa lalu, pendidikan, situasi psikis dan pengaruh lingkungan waktu itu (Sabarguna, 2004).

Kegiatan penyediaan berkas rekam medis di Rumah Sakit Rafflesia Kota Bengkulu dimulai dari pendaftaran, pencarian, pembuatan SEP dan SJP sampai pendistribusian ke poliklinik jantung sesuai standar pelayanan rawat jalan selama 10 menit. Jika kita bagi waktu 10 menit dengan 4 unit kegiatan, maka setiap waktu per unit pelayanan yaitu 2,5 menit.

Berdasarkan observasi pada masing masing unit pelayanan,pada bagian pendaftaran tidak terjadi keterlambatan, sedangkan pada unit pencarian terdapat 55 BRM yang melebihi waktu perunit pelayanan (> 2,5 menit), pada unit pembuatan SEP dan SJP terdapat 39 BRM yang melebihi waktu perunit pelayanan dan pada unit pendistribusian terdapat 53 BRM yang melebihi waktu perunit pelayanan. Hal ini dikarenakan pada saat melakukan kegiatan pencarian banyak berkas yang sulit untuk ditemui, tidak memiliki buku registrasi, tidak adanya SOP, sedangkan disaat pembuatan SEP \& SJP hanya dikerjakan oleh 1 orang petugas dan berkas lama didistribusikan ke ruang poliklinik 
jantung karena berkas ditumpuk untuk mengefisiensikan waktu dan tenaga petugas.

Hasil penelitian Mauren (2011) didapatkan bahwa masih didapatkan keterlambatan pendistribusian rekam medis di RSJ Soeharto Heerdjan Jakarta dengan rata-rata lama waktu 13 menit, antara lain karena kurangnya petugas rekam medis khususnya bagian pendistribusian serta lokasi pelayanan yang berbeda lantai dengan ruang penyimpanan sehingga menyebabkan keterlambatan pendistribusian rekam medis ke unit pelayanan. Pelayanan rekam medis yang baik dan bermutu tercermin dari pelayanan yang ramah, cepat, serta nyaman. Pelayanan rekam medis rawat jalan dimulai dari tempat pendaftaran pasien sampai memperoleh berkas rekam medis yang akan digunakan untuk mendapatkan pelayanan kesehatan. Berdasarkan standar waktu penyediaan berkas rekam medis rawat jalan adalah 10 menit (Kemenkes R.I, 2007).

\section{SIMPULAN}

Berdasarkan hasil penelitian dapat disusun kesimpulan sebagai berikut :

1. Dari 10 orang petugas rekam medisrawat jalan hanya satu orang berpendidikan D III Rekam Medis dan mayoritas masa kerja petugasnya kurang dari 5 tahun.

2. Pada saat pengambilan berkas rekam medis di ruangan filing, dari 105 berkas rekam medis mayoritas berkas sulit ditemuipada rak penyimpanan yaitu $62(59,1 \%)$ berkas rekam medis.

3. Dari 105 berkas rekam medis, $62(59,1 \%)$ berkas lambat disediakan oleh petugas rawat jalan, karena penyediaan berkas rekam medis lebih dari 10 menit.

\section{SARAN}

Berdasarkan hasil penelitian, maka disampaikan saran - saran sebagai berikut :
1. Penambahan SDM lulusan D III RM dan petugas Non RM diikuti pada pelatihan atau seminar.

2. Kepala ruangan melakukan pengawasan dalam penjajaran dan penyimpanan untuk mempermudah dalam pengambilan BRM

3. Fasilitas diruangan filing perlu ditambah seperti tangga, rak dan tanda petunjuk untuk berkas keluar (outguide/tracer).

\section{DAFTAR PUSTAKA}

Arfrida. 2003. Ekonomi Sumber Daya Manusia. Penerbit: Ghalia Indonesia

Andrian, F. D \& Sugiarti, I. 2015. Tinjauan Penyediaan Dokumen Rekam Medis di RSUD Dr. Soekardjo Kota Tasikmalaya, Jurnal Manajemen Informasi Kesehatan Indonesia, Vol.3, no. 2, Oktober 2015

Depkes RI. 1997. Pedoman Pengelolaan Rekam Medis Rumah Sakit di Indonesia Revisi I. Jakarta: Dirjen Yanmed.

Depkes R.I. 2006. Pedoman Penyelenggaraan dan Prosedur Rekam Medis Rumah Sakit di Indonesia. Revisi II. Jakarta: Dirjend Bina Pelayanan Medik, Depkes R.I

Departemen Kesehatan RI. Pedoman Penyusunan Perencanaan SDM kesehatan di Tingkat Provinsi, Kab/Kota serta Rumah Sakit. Jakarta: Direktorat Jenderal Pelayanan Medik, 2004

Giyana, F. Analisis Sistem Pengelolaan Rekam Medis Inap Rumah Sakit Umum Daerah Kota Semarang. Jurnal Kesehatan Masyarakat, Volume 1, Nomor 2, Tahun 2012, Halaman $48-61$. Online di http://ejournals1.undip.ac.id/index.php/jkm

Grossmann, M., 1999. The Human Capital Model of The Demand for Health. Cambridge: National Bureau of Economic Research

Jacobalis. 2000. Kumpulan Tulisan Terpilih Tentang Rumah Sakit Indonesia dalam Dinamika Sejarah, Transformasi, Globalisasi, dan Krisis Nasional. Yayasan Penerbit IDI, Jakarta.

Lasa Hs. 2005. Manajemen perpustakaan. Yogyakarta: Gama Media

Mauren, F. (2011).Tinjauan Lama Waktu Pendistribusian Rekam Medis Dilihat Dari Lokasi Penyimpanan Di RSJ Dr. Soeharto Heerdjan. Esa Unggul: KTI

Menteri Kesehatan Republik Indonesia. 2007. Keputusan Menteri Kesehatan republik Indonesia Nomor 377/Menkes/SK/ III/2007 
Tentang Standar Profesi Perekam Medis dan Informatika Kesehatan. Jakarta:Menteri Kesehatan

Menteri Kesehatan Republik Indonesia. 2010. Peraturan Menteri Kesehatan Nomor: 340/ Menkes/PER/III/2010 tentang Klasifikasi Rumah Sakit, Jakarta: Departemen Kesehatan Republik Indonesia.

Menteri Kesehatan Republik Indonesia. 2008. Peraturan Menteri Kesehatan Nomor: 269/MENKES/ PER/III/2008 Tentang Rekam Medis. Jakarta: Departemen Kesehatan Republik Indonesia

Nitisemito, A.S. 1996. Manajemen Personalia (Manajemen Sumber Daya Manusia) Jakarta: Ghalia Indonesia

Priansyah, D.J. 2014. Perencanaan dan Pengembangan Sumber Daya Manusia. Bandung: Alfabeta

Rustiyanto, E. (2009). Etika Profesi Dan hukum Kesehatan .Yogyakarta : Penerbit PI Press

Rustiyanto, E. 2010. Statistik Rumah Sakit untuk Pengambilan Keputusan. Yogyakarta : Graha Ilmu.

Sabarguna, B. 2004. Quality Assurance Pelayanan rumah Sakit. Yogyakarta : KonsorsiumRumah Sakit Islam Jateng

Siagian. 2008. Manajemen Sumber Daya Manusia. Jakarta: Bumi Aksara.

Sudrajat, I \& Sugiarti, I. 2014. Hubungan Kecepatan Penyediaan Dokumen Rekam Medis Rawat Jalan Dengan Tingkat Kepuasan Pasien. Jurnal Manajemen Informasi Kesehatan Indonesia, ISSN:2337-585X, Vol.3, No.1, Maret 2015

Susanti, T. 2013. Studi Tentang Kinerja Petugas Rekam Medis Di Rumah Sakit Persatuan Djamaah Haji Indonesia Yogyakarta. Program Studi Kesehatan Masyarakat Fakultas Ilmu Kesehatan Universitas Muhammadiyah Surakarta 2013. Skripsi

Wijono D, 2000. Manajemen Mutu Pelayanan Kesehatan Vol.2, Airlangga University Press, Surabaya.

Wintri, S. 2011. Sistem Penyimpanan dan Penjajaran Rekam Medis. Esa Unggul: KTI

Wursanto, IG. 2007. Kearsipan 2. Yogyakarta : Penerbit Kanisius. 
